\title{
Solid Phase Micro Tip Extraction Coupled With High Performance Liquid Chromatography for Diclofenac Sodium Analysis in Urine Sample
}

\author{
Dadan Hermawan ${ }^{1,2}$, Law Hui Ling ${ }^{3}$,Wan Aini Wan Ibrahim ${ }^{1,3}$, and Mohd Marsin Sanagi ${ }^{1,3}$ \\ ${ }^{1}$ Separation Science and Technology Group, Ibnu Sina Institute for Fundamental Science Studies, Universiti Teknologi Malaysia, 81310 UTM Johor Bahru, Johor Malaysia \\ ${ }^{2}$ Department of Chemistry, Faculty of Science and Engineering, Universitas Jenderal Soedirman, UNSOED Purwokerto, Jawa Tengah, Indonesia \\ ${ }^{3}$ Department of Chemistry, Faculty of Science, UTM, 81310 UTM Johor Bahru, Johor, Malaysia \\ Received 19 November 2012, Revised 14 February 2013, Accepted 16 February 2013, Available online 20 February 2013
}

\begin{abstract}
A solid phase micro tip extraction (SPMTE) has been developed as sample preparation technique for the analysis of diclofenac sodium, a non-steroidal anti-inflammatory drug (NSAID) in human urine sample. The analysis was performed by high performance liquid chromatography (HPLC) system using methanol:water $(60: 40, \mathrm{v} / \mathrm{v})$ as mobile phase, flow rate of $1.0 \mathrm{~mL} / \mathrm{min}$ under UV detection wavelength at $282 \mathrm{~nm}$. Extraction conditions such as desorption solvent and extraction time were optimized in this study. The optimized SPMTE coupled with the HPLC method was successfully applied for the determination of diclofenac sodium in urine samples. The best recovery of diclofenac sodium in urine samples is $74.80 \%$ with RSD of $3.56 \%$ ( $n=3$ ). The proposed method provides simple and rapid analysis of diclofenac sodium in urine sample.
\end{abstract}

| Diclofenac sodium | Solid phase micro tip extraction | HPLC | Urine sample | Anti-inflammatory drugs|

( 2013 Ibnu Sina Institute. All rights reserved http://dx.doi.org/10.11113/mjfas.v9n1.71

\section{INTRODUCTION}

Non-steroidal anti-inflammatory drugs, commonly abbreviated as NSAIDs, are one of the most commonly used medications in adults for the treatment of soft-tissue disorders coupled with pain and inflammation. There are two types of COX enzymes which are COX-1 and COX-2. Both of these COX enzymes produce prostaglandins within the body's cells that cause inflammation, fever, swelling and pain. The common mechanism of action for all NSAIDs is the inhibition of the enzyme cyclooxygenase (COX) and cut down the synthesis of prostaglandins throughout the body. NSAIDs can be taken orally, systemically, or by localized injection. The most common side-effect of NSAIDs is the irritation of the stomach, nausea and vomiting [1].

Diclofenac sodium is a non-steroidal antiinflammatory agent. Due to its strong analgesic, antipyretic and anti-inflammatory effects, it is used widely and clinically in human lives. It is specially used to cure pain, inflammations and dysmenorrhea. It is known that this drug inhibit biosynthesis of the prostaglandin in vivo and in vitro. Most importantly, it only considered to have little adverse gastrointestinal effects compared to other drugs that can causes bleeding from the stomach and intestines.

It is extensively metabolized in the liver and because of its short biological half-life, the drug has to be given frequently. For these reasons, diclofenac sodium can be considered as one of few non-steroidal anti-inflammatory drugs of for the first choice used in the healing of severe and chronic, painful and inflammatory conditions [2-3]

In this report, solid phase micro tip extraction (SPMTE) has been developed as sample preparation technique for the analysis of diclofenac sodium in human urine sample. The SPMTE conditions such as desorption solvent and extraction time were optimized in this study. The analysis was performed by high performance liquid chromatography (HPLC) using ultraviolet (UV) detector. Four HPLC conditions were optimized including the types of mobile phase, mobile phase composition, wavelength, and flow rate.

\section{EXPERIMENTAL}

\subsection{Materials}

Diclofenac sodium (99.1\% purity) was purchased from Sigma (St Louis, MO, USA). Methanol and acetonitrile (HPLC) grade were purchased from J. T. Baker, USA. Purified water was collected from a Millipore Simplicity (Simpak®2). All solvents are filtered through $0.45 \mu \mathrm{m}$ membrane prior to usage. Human urine samples were collected from a healthy drug-free volunteer.

\subsection{Instrumentation}

The HPLC system was an Agilent 1100 Series (Germany) and consisted of a Model Agilent 1100 pump, an 
on-line solvent vacuum degasser, an auto sampler with 20 $\mu \mathrm{L}$ injection loop, and an Agilent 1100 Series UV detector. The analytical column LichroCART ${ }^{\circledR}$ C18 $(150 \mathrm{~mm}$ x 4.6 $\mathrm{mm} \times 5 \mu \mathrm{m}$ particles) was obtained from Germany. The Agilent Chem Station software was used to record chromatograms and calculate peak area. The mobile phase consisted of a mixture of methanol and water $(60: 40 \mathrm{v} / \mathrm{v})$. The HPLC system was operated isocratically at a flow rate of $1.0 \mathrm{~mL} / \mathrm{min}$ and the effluent of the column was monitored at a wavelength of $282 \mathrm{~nm}$. An Agilent 1100 Series UV Spectrophotometer (Germany) was used to record the absorption maxima of analyte.

\subsection{Preparation of Standard Solution}

Stock solution of diclofenac sodium (1000 ppm) was prepared by dissolving $10 \mathrm{mg}$ of accurately weighed diclofenac sodium standard in methanol. The standard working solutions of $0.5,1.0,5.0$ and $10.0 \mathrm{ppm}$ was prepared from the stock solution using methanol. The stock solution and all standards were labeled, sealed and wrapped with aluminium foil to avoid evaporation of the solutions and were stored in the refrigerator at $5{ }^{\circ} \mathrm{C}$ until needed. Working solutions with selected concentrations were prepared by diluting appropriate amounts of the standard working solution with methanol.

\subsection{Urine Sample Preparation}

Blank human urine sample was first analyzed to make sure that it does not contain any analyte of interest. Spiked human urine samples with diclofenac sodium was then analyzed. For the sample pretreatment, the human urine samples were filtered using $0.22 \mu \mathrm{m}$ filter membrane.

\subsection{Extraction Procedure}

The isolation of diclofenac sodium from human urine was conducted by SPMTE using carbon nanotube (CNT) as sorbent. This procedure was adopted from previous study [4]. A $15 \mathrm{~mL}$ of each spiked urine sample was placed into a sample vial and stirred at $1000 \mathrm{rpm}$ where the solid phase membrane tip was then placed in it. By using a micropipette (Nichiryo, Japan), $600 \mu \mathrm{L}$ of aqueous sample was withdrawn manually into the tip at rate of approximately 30 $\mu \mathrm{L} / \mathrm{s}$. The withdrawn sample was then released back into the sample vial at same speed after holding it for about 3 seconds. The micropipette was detached from the tip after the steps stated above were repeated for 5 times. The overall extraction procedure was repeated at every 5 min interval until the end of extraction. After extraction, the cone-shaped membrane was removed and rinsed in ultra-pure water. Then, it was dried by using a lint-free tissue and placed in a $500 \mu \mathrm{L}$ safe-lock tube. By ultasonication in methanol (200 $\mu \mathrm{L}$ ), the analytes were desorbed and $5 \mu \mathrm{L}$ was subsequently injected into the HPLC-UV for detection.

\section{RESULTS \& DISCUSSION}

\subsection{Optimization of HPLC System}

For the HPLC optimization, four parameters were studied including types of mobile phase, mobile phase composition, wavelength and flow rate. The optimized conditions for separation of diclofenac sodium is using methanol:water $(60: 40, \mathrm{v} / \mathrm{v})$ at a flow rate of $1 \mathrm{~mL} / \mathrm{min}$ under wavelength of $282 \mathrm{~nm}$. Fig. 1 shows a typical chromatogram of diclofenac sodium under the optimized HPLC method.

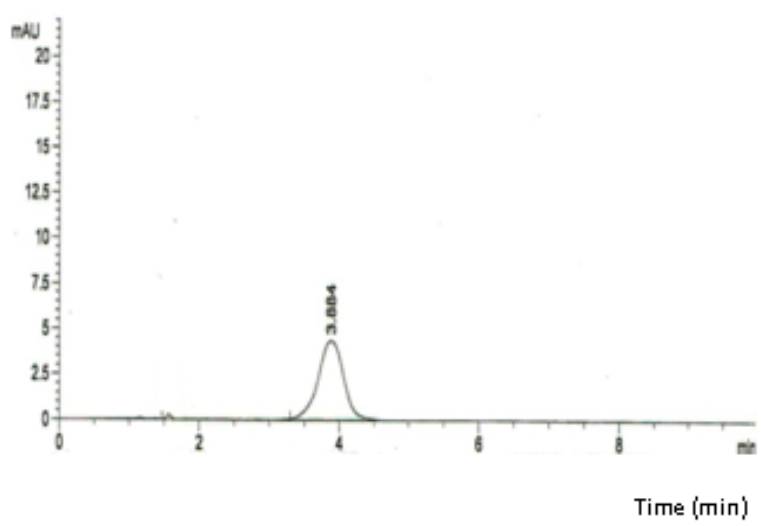

Fig. 1. Chromatogram of diclofenac sodium by the optimized HPLC method. Conditions: C18 column $(150 \mathrm{~mm} \times 4.6 \mathrm{~mm} \times$ $5 \mu \mathrm{m})$; flow rate $1.0 \mathrm{~mL} / \mathrm{min}$; ultraviolet (UV) detector: wavelength $282 \mathrm{~nm}$; volume of injection: $5 \mu \mathrm{L}$

\subsubsection{Optimization of Mobile Phase Types}

Three types of mobile phase have been investigated in this study, i.e. methanol:acetonitrile, acetonitrile:water and methanol:water. It was found that only methanol:water can give a full separation between the diclofenac sodium peak and the solvent peak (data not shown). By using other two types of mobile phase, both of these peaks have been unexpectedly overlapped. This has proven that methanol:acetonitrile and acetonitrile:water are not suitable for the separation of diclofenac sodium. Thus, methanol:water was chosen as the optimum mobile phase for further analysis.

\subsubsection{Optimization of Mobile Phase Composition}

Different composition of methanol:water as mobile phase i.e. $(90: 10, \mathrm{v} / \mathrm{v}),(80: 20, \mathrm{v} / \mathrm{v}),(70: 30, \mathrm{v} / \mathrm{v})$ and $(60: 40$, $\mathrm{v} / \mathrm{v}$ ) were investigated. The analyte peak and solvent peak are overlapped in methanol:water $(90: 10, \mathrm{v} / \mathrm{v}),(80: 20, \mathrm{v} / \mathrm{v})$ and $(70: 30, v / v)$ due to their fast elution time. Only methanol:water (60:40, v/v) can give a full separation between these two peaks (data not shown). This is probably because diclofenac sodium is freely soluble in methanol but sparingly soluble in water [5]. The decrease in percentage of methanol will lower the solubility of diclofenac sodium 
in mobile phase. The analyte is eluted slower resulting in longer retention time and full separation can be attained. Therefore, methanol:water $(60: 40, \mathrm{v} / \mathrm{v})$ was used as the optimum condition for further analysis.

\subsubsection{Optimization of wavelength}

Four different wavelengths, $254 \mathrm{~nm}, 270 \mathrm{~nm}, 282$ $\mathrm{nm}$ and $284 \mathrm{~nm}$ were investigated in this study. The variation of wavelength does not give large effect on retention time and retention factor. However, their peak area was increased following the increment of wavelength. However, the peak area has been decreased at $284 \mathrm{~nm}$ (data not shown). At higher wavelength, the molar absorptivity of diclofenac sodium is relatively high, but the maximum UV absorption was attained at $282 \mathrm{~nm}$. Hence, $282 \mathrm{~nm}$ with highest peak area was chosen as the optimum wavelength for this research.

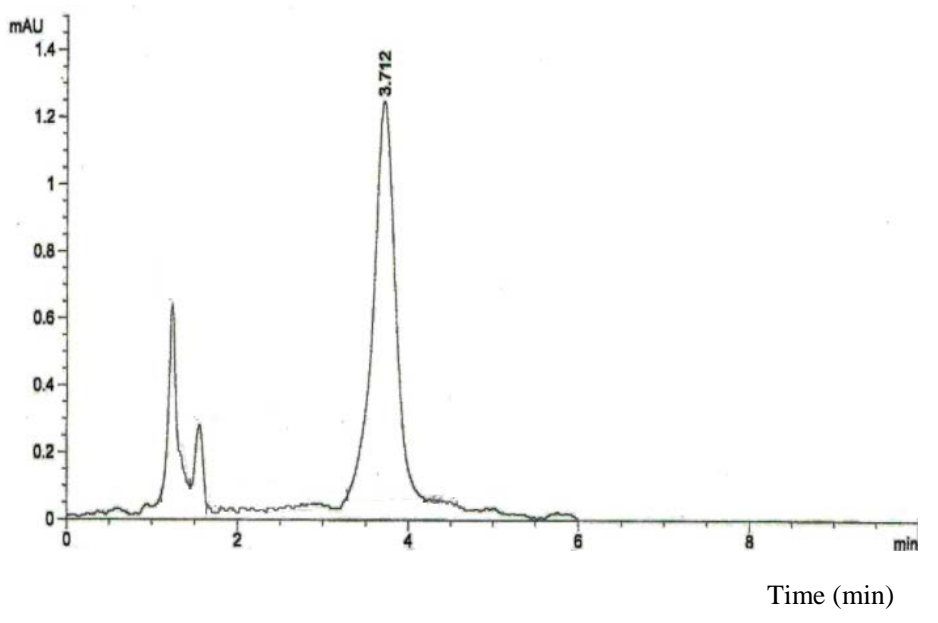

Fig. 2. Chromatogram of diclofenac sodium by the optimized SPMTE-HPLC method. Conditions as in Fig.1.
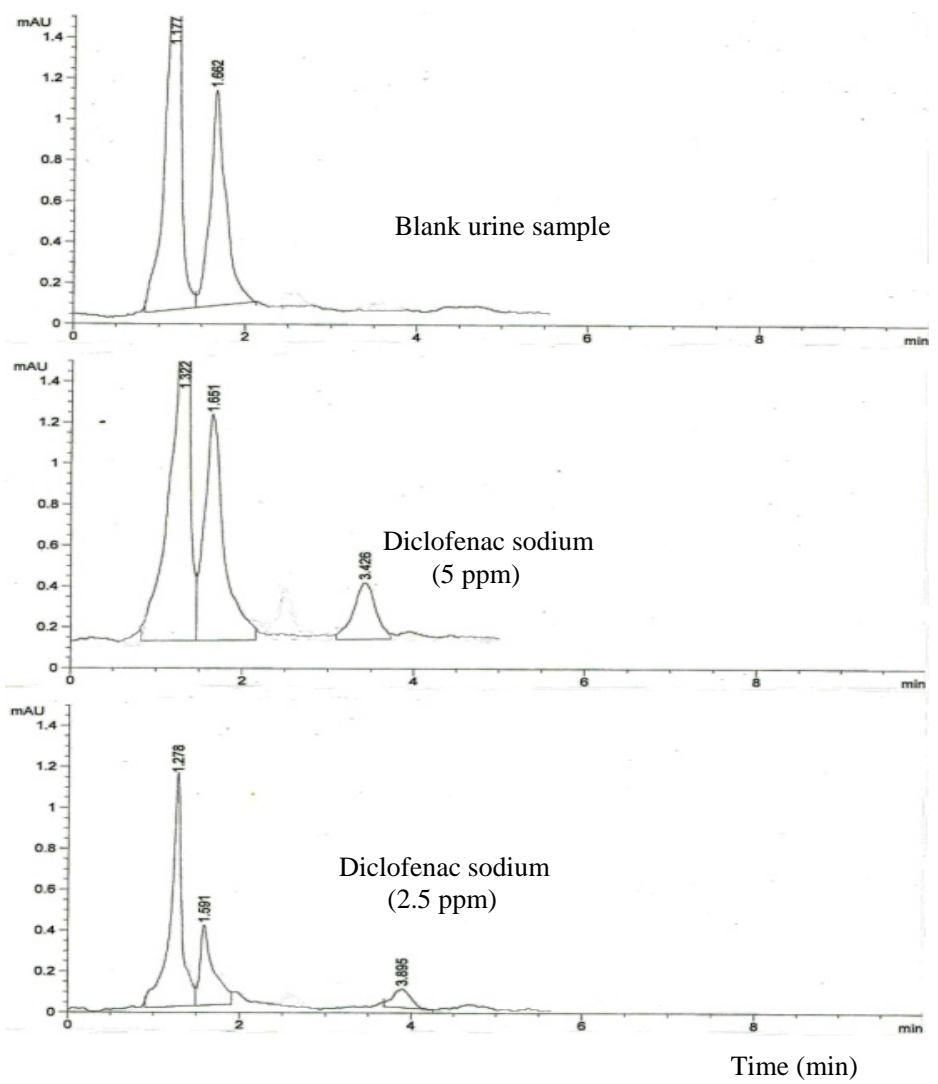

Fig. 3. Chromatogram of blank and spiked urine samples by SPMTE-HPLC method. HPLC conditions: as in Fig. 1. 


\subsubsection{Optimization of flow rate}

Four different flow rates at $0.5 \mathrm{~mL} / \mathrm{min}, 0.6 \mathrm{~mL} / \mathrm{min}$, $0.8 \mathrm{~mL} / \mathrm{min}$ and $1.0 \mathrm{~mL} / \mathrm{min}$ were studied. It was found that the retention time increases as the flow rate of mobile phase decreases (data not shown). This probably because when the flow rate is low, the time given for the interaction between the analyte and stationary phase to be happen is longer. So, diclofenac sodium was slowly eluted. Due to the effects of retention time on the peak shape, longer retention time will results in broader peak. Since at $1.0 \mathrm{~mL} / \mathrm{min}$, sharp peak and full separation between analyte peak and solvent peak is attained, it was chosen as the optimum flow rate for analysis of diclofenac sodium in this study.

\subsection{Optimization of SPMTE System}

In this study, the types of desorption solvent and extraction time were investigated. The optimum conditions for SPMTE were methanol as desorption solvent and 25 minutes of extraction time. Fig. 2 shows the chromatogram obtained under optimized conditions for SPMTE.

\subsubsection{Optimization of Desorption Solvent}

It was found that methanol gave a higher peak area to diclofenac sodium (data not shown). As diclofenac sodium is freely soluble in methanol and slightly soluble in acetonitrile, methanol can desorb diclofenac sodium more effectively from MWCNTs as compared to acetonitrile. In this study, methanol was chosen as the desorption solvent in SPMTE system.

\subsubsection{Optimization of Extraction Time}

The results showed that peak area increase as the extraction time increase (data not shown). The highest extraction was achieved at 25 minutes. This is probably because at this extraction time, sufficient time is given for mass-transfer of diclofenac sodium to be happening onto CNT and equilibrium has been attained. Hence, 25 minutes has been chosen as the optimum extraction time.

\subsection{Analytical Performance of the Method}

The optimized HPLC method for determination of diclofenac sodium ranging from $1 \mathrm{ppm}$ to $10 \mathrm{ppm}$ shows good correlation coefficients, $r>0.999$. The limit of detection (LOD) and limit of quantitation (LOQ) obtained were $0.28 \mathrm{ppm}$ and $0.94 \mathrm{ppm}$ respectively. The calibration graph of SPMTE-HPLC method also gave an excellent linearity with $r>0.999$. The LOD and LOQ obtained were $0.52 \mathrm{ppm}$ and $2.84 \mathrm{ppm}$ respectively. This results show that the optimized method is sensitive for the analysis of diclofenac sodium in urine samples.

\subsection{Real Sample Analysis}

The optimized SPMTE coupled with HPLC method was used for the determination of diclofenac sodium in blank and spiked urine samples. The recovery of diclofenac sodium from human urine samples was done by comparing the peak area of the real samples with the calibration graph of standards with known concentrations. The best recovery of diclofenac sodium in urine samples was $74.80 \%$ with RSD $(n=3)$ of $3.56 \%$. Fig. 3 shows the chromatogram of blank and spiked urine samples by the optimized SPMTEHPLC conditions.

\section{CONCLUSION}

In this study, the quantitative determination of diclofenac sodium in urine sample was carried out by the optimized SPMTE-HPLC-UV with methanol:water (60:40, $\mathrm{v} / \mathrm{v})$ at $1.0 \mathrm{~mL} / \mathrm{min}$ flow rate under $282 \mathrm{~nm}$. Injection volume used was $5 \mu \mathrm{L}$. In the optimized SPMTE method, methanol was used as desorption solvent while extraction was done in a period of 25 minutes. Calibration graphs were linear in the range from $1 \mathrm{ppm}$ to $10 \mathrm{ppm}$ with coefficient of determination of 0.999 . For the calibration graph of HPLC, LOD was $0.28 \mathrm{ppm}$ and LOQ was $0.94 \mathrm{ppm}$ while calibration graph of SPMTE-HPLC, LOD and LOQ were $0.52 \mathrm{ppm}$ and $2.84 \mathrm{ppm}$ respectively. It was shown that the optimized SPMTE coupled with HPLC method was successfully applied for the determination of diclofenac sodium in human urine samples with the best recovery of $74.80 \%$ with RSD $3.56 \%(n=3)$.

\section{ACKNOWLEDGEMENT}

The financial support provided by the Ministry of Higher Education Malaysia (MOHE) through the Fundamental Research Grant Scheme (FRGS) vote number 78669 is gratefully acknowledged.

\section{REFERENCES}

[1] R.R. Nageswara, V. Nagaraju, J. Pharm.and Biomed. Anal. 33 (2003) 335-376.

[2] A. Nokhodchi, K. Sharabiani, M.R. Rashidi, T. Ghafourian, Int. J. of Pharm. 335 (2007) 97-105.

[3] M.L. Fernandez de Cordova, P.O. Barrales, A.M. Dõaz, Anal. Chim. Acta. 369 (1998) 263-268.

[4] H.H. See, M.M. Sanagi, W.A. Wan Ibrahim, A.A. Naim, J. Chromatogr. A., 1217 (2010) 1767-1772.

[5] Q.A. Xu, T.L. Madden, Analytical Methods for Therapeutic Drug Monitoring and Toxicology, Wiley \& Sons, Inc., New Jersey, 2011. 